Wilfrid Laurier University

Scholars Commons @ Laurier

2006

\title{
Adolescents' self-attributed moral emotions following a moral transgression: relations with delinquency, confidence in moral judgment, and age
}

Tobias Krettenauer

Wilfrid Laurier University, tkrettenauer@wlu.ca

Dana Eichler

Follow this and additional works at: https://scholars.wlu.ca/psyc_faculty

Part of the Developmental Psychology Commons

\section{Recommended Citation}

Krettenauer, T., \& Eichler, D. (2006). Adolescents' self-attributed moral emotions following a moral transgression: Relations with delinquency, confidence in moral judgment and age. British Journal of Developmental Psychology, 24(3), 489-506. https://doi.org/10.1348/026151005X50825

This Article is brought to you for free and open access by the Psychology at Scholars Commons @ Laurier. It has been accepted for inclusion in Psychology Faculty Publications by an authorized administrator of Scholars Commons@Laurier. For more information, please contact scholarscommons@wlu.ca. 
Running head: ADOLESCENTS' SELF-ATTRIBUTED MORAL EMOTIONS

Adolescents' self-attributed moral emotions following a moral transgression: relations with delinquency, confidence in moral judgment, and age

Tobias Krettenauer \& Dana Eichler

Humboldt University at Berlin

Krettenauer, T., \& Eichler, D. (2006). Adolescents' self-attributed moral emotions following a moral transgression: Relations with delinquency, confidence in moral judgment and age. British Journal of Developmental Psychology, 24(3), 489-506. https://doi.org/10.1348/026151005X50825

Tobias Krettenauer, Institute for Psychology, Humboldt University at Berlin, Berlin, Germany; Dana Eichler, Department of Education, Humboldt University at Berlin, Berlin, Germany.

The research reported in this paper is part of larger research project that was supported by the German Research Foundation (Grant KR2027/3-1/2). Results from other parts of this project were published in Krettenauer (2004) and Krettenauer (in press).

The authors would like to thank Charles C. Helwig, David Moshman and one anonymous reviewer for their valuable comments on earlier versions of the manuscript.

Correspondence concerning this article should be addressed to: Tobias Krettenauer, Humboldt University at Berlin, Institute for Psychology, Unter den Linden 6, 10099 Berlin. E-mail: tobias.krettenauer@rz.hu-berlin.de. 


\begin{abstract}
The study investigates adolescents' self-attributed moral emotions following a moral transgression by expanding research with children on the happy-victimizer phenomenon. In a sample of 200 German adolescents from Grades 7,9, 11 , and $13(M=16.18$ years, $S D=2.41)$, participants were confronted with various scenarios describing different moral rule violations and asked to judge the behavior from a moral point of view. Subsequently, participants' strength of self-evaluative emotional reactions was assessed as they were asked to imagine that they had committed the moral transgression by themselves. Results indicate that the intensity of self-attributed moral emotions predicted adolescents' self-reported delinquent behavior even when social desirability response bias was controlled. Further, as adolescents' metacognitive understanding of moral beliefs developed, self-attributed moral emotions and confidence in moral judgment became more closely associated. No general age-related change in adolescents' self-attributed moral emotions was found. Overall, the study provides evidence for a coordination process of moral judgment and moral emotion attributions that continues well beyond childhood and that corresponds with the more general notion of the formation of a moral self in adolescence.
\end{abstract}


Adolescents' self-attributed moral emotions following a moral transgression: relations with delinquency, confidence in moral judgment, and age

Previous research has provided ample evidence that children acquire an understanding of moral rules that is intrinsically motivating quite early in development. Three- to four-year-olds consider particular behaviors as immoral and are motivated to abstain from such behaviors not because of authoritative commands or the threat of punishment (as Kohlberg's theory suggested), but because of the harm that is done to the victim (see e.g. Smetana, 1995; Turiel, 1998; Nucci, 2001). This intrinsic understanding of moral rules is fairly robust over the course of development. It becomes increasingly coordinated with other domains of social knowledge (Smetana, 1995) and integrated into more general developmental systems. Owing to this process of coordination and integration, moral development is not restricted to early childhood but continues well into adolescence and adulthood. As indicated by an increased consistency of judgment and action that is associated with more mature types and levels of moral reasoning (cf. Kohlberg \& Candee, 1984; Gibbs et al. 1986), additional motivational sources for moral action are formed in the course of development. Damon (1996) and Blasi (1993, 1995) suggested that this increased consistency of moral judgment and action results from the development of a moral self. According to this view, moral reasoning and self-understanding are two independent developmental systems that become gradually integrated in the course of development. Owing to this integrating process moral beliefs cease to occupy a status external to the self and become an integral part of an individual's selfdefinition (for an extensive discussion of the notion of an integration of self and morality, see Bergman, 2002).

Damon (1996) argued that adolescence is critical for the formation of a moral self. However, the development of moral motivation is not limited to the adolescent years, as indicated, for instance, by research on the so called "happy-victimizer phenomenon". This line of research demonstrated that young children, despite of their intrinsic understanding of moral rules, tend to attribute positive emotions to a wrongdoer who commits an immoral act in order to achieve a desired goal. Moral emotion attributions as assessed by the happy-victimizer research paradigm turned out to be associated with children's actual behavior in various experimental as well as natural settings (Asendorpf \& Nunner-Winkler, 1992; Nunner-Winkler, 1999). Children who attribute positive emotions to a moral wrongdoer evidenced more egoistic and more aggressive behavior 
(Hughes \& Dunn, 2000; Malti, 2003). Happy victimizer attributions generally decline over the course of development. Thus, with development, children's understanding of moral rules, on the one hand, and their understanding of moral emotions as experienced by an actor committing an immoral action, on the other, becomes increasingly coordinated. This coordination process fosters children's motivation to act in accordance with what they consider right from a moral point of view (see also Nunner-Winkler \& Sodian, 1988; Harris, 1989).

Although there is some disagreement about the precise nature of developmental change in children's emotion attributions and its exact relation to age (cf. Yuill, Perner, Pearson, Peerbhoy, \& van den Emde, 1996; Keller, Lourenço, Malti, \& Saalbach, 2003), the finding that younger children tend to attribute positive emotions to a wrongdoer in spite of knowing that an act is morally wrong was replicated many times (e.g. Arsenio \& Kramer, 1992; Lourenço, 1997, Murgatroyd \& Robinson, 1993; 1997; Wiersma \& Laupa, 2000). However, while focusing on children's development, the question of developmental change in emotion attributions occurring after childhood, i.e. in adolescence, has been largely neglected so far. If emotion attributions as assessed by the happy-victimizer research paradigm are related to individuals' moral motivation and if adolescent development is characterized by a further integration of self and morality that forms an additional motivational source for moral action, as Damon (1996) suggested, changes in adolescents' moral emotion attributions can be reasonably expected. The present study aims at investigating such changes by extending the happy-victimizer research paradigm and by considering adolescents' self-attributed moral emotions following a moral transgression in the broader context of adolescent development. This research examines the extent to which moral emotion attributions predict adolescents' delinquent behavior. Moreover, the study investigates whether there is an increased consistency of moral emotion attributions and confidence in moral judgment as part of the more general developmental dynamic related to the formation of a moral self. These issues are further elaborated and more specific hypotheses are formulated below. But first, a more general methodological statement on the study's approach to adolescents' moral emotion attributions is needed.

Certainly, any investigation of moral emotion attributions in adolescence requires important modifications of the original happy-victimizer research paradigm. It is evident that stories typically used in studies with children (e.g. a child pushes another child off a swing because she wants to 
play and there is only one swing on the playground) would be inappropriate, since scenarios describing moral transgressions must be relevant to adolescents. Moreover, as adolescents might be more concerned with self-presentation in an interview situation than children, social desirability response bias needs to be taken into consideration as a possible confound regarding all moral emotion attributions. Most importantly, the response format for emotion attributions needs to be modified. Happy-victimizer research with children focuses on the shift in the valence of emotion attributions (from 'feeling good' to 'feeling bad'). Studies with children repeatedly demonstrated that this shift occurs in childhood. Thus, it is highly probable that virtually all adolescents would anticipate bad feelings when committing an immoral action, at least to some extent. However, shifts in the valence of emotion attributions are not the only kind of change that may occur in the course of development. There might be developmental change in the intensity of self-evaluative emotional reactions even if happy-victimizer attributions have disappeard in this age period. The present study thus will focus on the intensity of self-evaluative emotional reactions following a moral transgression rather than on the shift in the valence of emotion attributions. By focusing on the intensity of emotional responses it becomes possible to investigate changes in moral emotion attributions in adolescence, even if the happy-victimizer phenomenon as such (good feelings after a moral transgression) may have disappeared in this age-period.

Adolescents' moral emotion attributions and delinquent behavior. Theoretically, the intensity of the self-evaluative emotional reactions following a moral transgression is considered as an indicator of adolescents' moral motivation strength. Adolescents who anticipate less intense negative self-evaluative emotions when committing an immoral action in order achieve a desired goal are probably less motivated to abstain from such actions because, in situations where morality and self-interest conflict, they experience the reasons for doing what is morally right as less important to themselves. As a consequence, these adolescents might be more frequently involved in delinquent behavior that is typical for their age (e.g. shop-lifting, minor forms of fraud). This hypothesis will be tested empirically.

Adolescents' moral emotion attributions, confidence in moral judgment and the formation of a moral self. Various developmental dimensions contribute to the integration of self and morality and to the formation of a moral self in the adolescent years. On the one side, there are changes in adolescent self-understanding that make it possible for adolescents to integrate moral ideals into 
their self-concept (Damon \& Hart, 1988). On the other side, there are changes in adolescents' metacognitive understanding of human knowledge, in general, and moral knowledge, in particular, that facilitate the integration of moral beliefs into more personal belief systems. Evidence for such changes in adolescents' metacognitive understanding comes from research on the development of epistemic cognition.

Research on epistemic cognition has provided ample evidence for three main levels that represent important milestones in the course of adolescents' epistemic reasoning development (for an overview see Hofer \& Pintrich, 1997; Kitchener, 2002; Moshman, 2005): In an early period of development, knowledge, in general, is understood as a direct copy of external reality. The sole source of knowledge is the external world. This conception of knowledge and knowing changes markedly once individuals attain the subsequent, multiplistic stance. A multiplist understands knowledge as mainly determined by one's personal point of view. Thus, the self is the source of knowledge. Finally, these polar extremes of absolutism versus multiplism are brought into a more balanced, evaluativist position (Kuhn, Cheney \&Weinstock, 2000). On this level, different ideas and viewpoints can be evaluated without appealing to ultimate standards of right and wrong. Nonetheless, choosing between different viewpoints is not merely considered a matter of personal preference because one viewpoint may be preferable on grounds that can be meaningfully debated.

Research on the development of epistemic cognition demonstrated that, despite considerable domain specificity in the timing of developmental transitions, individuals' epistemic reasoning follows similar developmental trajectories in different domains of knowledge (Kuhn et al. 2000; Hallett, Chandler, \& Krettenauer, 2002; Mansfield \& Clinchy, 2002). Regarding adolescents' epistemic cognition in the moral domain (in the following also referred to as metaethical cognition) three developmental levels or stances were identified that are structural analogues of the three main levels of epistemic cognition outlined above (these metaethical stances were dubbed: intuitionism, subjectivism and transsubjectivism; for further details see Krettenauer (2004) and method section). Krettenauer (2004) demonstrated that in the course of adolescent development individuals regularly achieve a subjectivist metaethical stance. ${ }^{1}$

The development of metaethical subjectivism is probably associated with significant changes in adolescents' moral emotion attributions as investigated in the present study: Metaethical subjectivists, by definition, consider subjective emotions aroused by the contemplation of a moral 
problem as an important criterion for moral decision-making. At the prior intuitionist level, in contrast, moral judgments are understood analogously to visual perception: one simply "sees" whether an action is right or wrong; the rightness or wrongness of an act is thus self-evident. Whereas metaethical intuitionists are unable to explicate the source of their moral knowledge, subjectivists consider personal feelings as an important source of this knowledge. Thus, along with the development of metaethical reasoning the conditions change that need to be satisfied for being confident that one's moral judgment is correct: At the intuitionist level confidence depends primarily on the demand characteristics of a given situation. If these demand characteristics are strong and unambiguous confidence in moral judgment is high. At the subjectivist level (and beyond), by contrast, the subjective emotions aroused by the contemplation of a moral problem are given more weight than at the prior intuitionist level. As a consequence, the association between the intensity of self-attributed moral emotions and confidence in moral judgment may be strengthened once adolescents develop a subjectivist metaethical understanding. This hypothesis will be tested empirically.

An increase in the consistency of confidence in moral judgment, on the one hand, and selfattributed moral emotions, on the other, as postulated in this study, would correspond with the general notion of an integration of self and morality in adolescence. At the same time, as should be explicitly noted at this point, it would be in full harmony with the well-documented finding that individuals regardless of their age consider moral rules as universally binding and independent of people's subjective desires (Turiel, 1998; Nucci, 2001). The development of metaethical subjectivism that is associated with adolescents' epistemic reasoning is metacognitive (cf. Kuhn, 1999) and not normative. Thus, even if individuals know that particular actions are wrong because of certain non-subjective features of these actions (e.g. their harmfulness), when asked epistemological questions about these normative beliefs they may adopt a pure subjectivist position and refer to personal feelings as the source of their moral knowledge. Thus, individuals' normative judgments and their metaethical position are not necessarily well-coordinated. Kuhn et al. (2000) pointed out that such a tension between individuals' thinking about various aspects of the world and their epistemological reasoning is pervasive, in particular in adolescence.

Adolescents' moral emotion attributions and age. Age-related changes in moral emotion attributions have been studied only in childhood, so far. While the basic finding that younger 
children attribute positive emotions to a wrongdoer in spite of knowing that an act is morally wrong was replicated many times, considerable disagreement emerged regarding age-related change. Some researchers reported strong age-related changes so that the happy victimizer-phenomenon had virtually disappeared around the age of 10 years; others provided evidence that many children attribute positive emotions to a moral wrongdoer even in late childhood (for an overview see Keller, Lourenço, Malti, \& Saalbach, 2003). In three smaller studies, Murgatroyd and Robinson compared responses of young adults with responses of older children (Murgatroyd \& Robinson, 1993, Study 4; Murgatroyd \& Robinson, 1997, Study 3 and 4). The authors did not find substantial differences between the two age groups. This might indicate that there is no general developmental change in moral emotion attributions in adolescence. However, as the studies by Murgatroyd and Robinson did not compare different age groups of adolescents their studies were not suitable to reveal age-related change within this developmental period. In the present study, age-related change in the intensity of self-attributed moral emotions are explored. Such an exploration might help to clarify the developmental nature of moral emotion attributions that is still controversial in happyvictimizer research with children.

In sum, then, the present study is meant to investigate adolescents' self-attributed moral emotions when committing an immoral act in the broader context of adolescent development. Theoretically, the following two findings are expected: (1) The intensity of self-attributed moral emotions following a moral transgression should predict adolescents' engagement in delinquent behavior. (2) The association between the intensity of self-attributed moral emotions, on the one hand, and confidence in moral judgment, on the other, should increase once adolescents have achieved the subjectivist level of metaethical reasoning. In addition to testing these two hypotheses, age-related changes in the intensity of adolescents' self-attributed moral emotions are explored.

\section{Method}

\section{Participants}

The sample of the present study was composed of 200 adolescents equally distributed over four different grade levels (Grade 7, 9,11 and 13) with equal numbers of males and females in each age group. Mean ages for the four groups were as follows: 13.14 years $(S D=0.62)$ for Grade 7; $15.01(S D=0.41)$ for Grade $9 ; 17.15$ years $(S D=0.54)$ for Grade 11 ; and $19.39(S D=0.66)$ for

Grade 13. The sample was drawn from five different high schools located in socially heterogeneous 
quarters of East and West Berlin. All adolescents were Caucasian; most of them were born in either West- or East-Germany (47\% and $43.5 \%$, respectively). The sample was predominantly middleclass according to Treiman's (1977) Standard International Occupational Prestige Scale, with an average occupational status score of parents of $M=49.6(S D=11.9$, range $=21-78)$, a score reflecting occupations such as nurse or technician.

Research participants volunteered in response to an advertisement distributed in their schools. Each was given an honorarium of 15 EURO. For adolescents younger than 18 years informed consent for participating in the study was given by one of the parents. Participants who were 18 years old or older had provided informed consent by themselves.

\section{Measures and Procedures}

In the study participants completed a questionnaire and participated in a semi-structured interview of about 45 minutes. The questionnaire was administered in group sessions. The interview was conducted individually, audio-recorded and later transcribed. The questionnaire assessed social desirability response bias as well as adolescents' engagement in delinquent behavior. The interview was designed to assess adolescents' self-attributed moral emotions with regard to various moral transgressions as well as their metaethical stance.

\section{Interview}

In the interview six vignettes were presented that confronted participants with different moral problems. Two vignettes described moral dilemmas that were designed to assess adolescents' metaethical position. The other four vignettes described moral transgressions similar to those used in the happy-victimizer research paradigm. They were used to assess adolescents' self-attributed emotions following a moral transgression as well as their confidence in moral judgment.

Self-attributed moral emotions and confidence in moral judgment. Each of the four vignettes that were used to assess adolescents' self-attributed moral emotions described a person committing an immoral act in order to satisfy his or her personal interests (for the full text of the scenarios see Appendix A). The scenarios described a variety of different moral rule violations. One scenario (hereafter referred to as Story I) portrayed a young woman who gave false testimony in a court hearing in order to gain a desired job. The second scenario (hereafter referred to as Story II) described a man absconding from the scene of a traffic accident because he had been drunk and driving. The third scenario described an adolescent not returning a found wallet to the owner (Story 
III), in the fourth scenario a student was described who stole a desired object from a flea market salesman (Story IV). The scenarios were presented in different order (ordering A: Stories I-III-IIIV; ordering B: Stories II-IV-I-III). Half of the participants (randomly chosen) received version A, and the other half version B of the interview.

After presenting the scenarios, participants were asked to evaluate the protagonist's behavior from a moral point of view: Was the person right to do what he or she did? Overall, 192 participants (96\%) consistently considered the described behaviors as morally wrong across all scenarios. For these participants negative self-evaluative moral emotions can be reasonably expected in the scenarios. This is not true for the other eight respondents who were therefore omitted from all further analyses.

After asking respondents whether what the protagonist did was right, confidence in moral judgment were assessed by the additional question "How certain are you that your view is correct?". Respondents were asked to provide their answer by choosing between the following response categories: $1=$ uncertain , $2=$ a little uncertain, $3=$ a little certain, $4=$ certain , $5=$ very certain and $6=$ absolutely certain . Because all four scenarios depicted an obvious immoral action in order to obtain a desirable outcome (correspondingly all four actions were almost consensually considered wrong by respondents) it is reasonable to sum individuals' responses across scenarios in order to enhance the reliability of the study's assessment of confidence in moral judgment. The internal consistency of adolescents' responses regarding their confidence in moral judgment across the four scenarios was satisfactory, with Cronbach's- $\alpha$ of .63 .

Self-attributed moral emotions were assessed separately for each scenario by the following questions: "Imagine you did what ... [name of the protagonist in the story added] ... has done. How would you feel afterwards?". Again, respondents had to provide their answers by choosing between preformulated response categories. Overall, there were six response categories: $1=$ not bad, $2=a$ little bad, $3=$ moderately bad, $4=$ bad, $5=$ very bad and $6=$ extremely bad . These response categories reflect the strength of adolescents' self-evaluative moral emotions when committing an immoral act. Considering all four scenarios together, a scale analysis indicated satisfactory consistency of adolescents' emotion attributions, with a Cronbach's- $\alpha$ of .65 . Averaged across the four scenarios, the grand mean of adolescents' emotion attributions was $M=4.53(S D=0.91)$, 
indicating an average intensity of moral emotions between 'bad' and 'very bad'. No effect of story order (A vs. B) was found, $F(4,178)=1.19, p=.317$. Across all four scenarios, 12 (out of 192) participants had chosen the response category 'not bad' once and four participants opted for this response in two scenarios. If this response pattern is taken as an instance of the happy-victimizer phenomenon, happy victimizers were thus fairly infrequent in the present sample.

Metaethical stance. To assess adolescents' metaethical stance, respondents were confronted with a moral dilemma and asked what the protagonist should do in the situation. After respondents had made a decision, four issues that represent various themes of metaethical reasoning were addressed, each by a leading question and further probing (for a detailed description of the interview and scoring procedure see also Krettenauer, 2004). Two issues, (a) certainty of moral judgment and (b) relativity of moral judgment, reflect beliefs about the nature of moral judgments. The other two issues, (c) mechanisms of belief change and (d) sources of decision-making represent individuals understanding of the process of moral judgment formation. The interview questions to assess metaethical cognition regarding these issues were as follows (translated from German): (a) Is there anything regarding your decision that makes you feel uncertain? Why does this make you feel uncertain? (certainty); (b) In thinking about your decision, would you say that there is one and only one right answer or are there different views regarding the problem which are equally good? Why? (relativity); (c) Could you imagine changing your viewpoint? How come that people change their view regarding such a problem? (mechanisms of belief change); (d) Imagine that before making a decision you had the opportunity to ask somebody else for advice? Whom would you like to ask? Why would it be helpful for you to ask this person for advice? (sources of decision-making). There were two moral dilemmas. For these two dilemmas the leading questions were posed almost identically, with only minor variations in the wording.

For the four issues more specific scoring criteria were formulated that correspond with the general conception of epistemic stances as outlined in the introduction (for an overview of these scoring criteria see Appendix B). All four issues were scored separately for each dilemma. The scoring procedure yielded eight scores representing respondents' metaethical position across four issues and two dilemmas. Individuals were assigned to that metaethical position they had most frequently adopted across issues and dilemmas (modal score). On average, $77.3 \%$ of interview responses across the four issues and two dilemmas reflected respondents' modal score. 
For the modal score exact interrater agreement between two independent raters in a randomly selected subsample of 40 interviews equaled $84.2 \%$ with a Cohen's- $\kappa$ of .70 . Overall, $32.3 \%$ of participants were classified as intuitionists, $60 \%$ of participants were assigned to the subjectivist position, whereas only a minority of $7.7 \%$ were classified as transsubjectivists. Four cases had their modal score on two positions and were therefore not assigned to an overall metaethical position.

Since the differentiation between subjectivism and transsubjectivism as two distinct developmental achievements will be left out of consideration in the context of the present study (see Footnote 1) only two groups of adolescents will be compared when analyzing the association between confidence in moral judgment and intensity of moral emotion attributions: Those who have not yet achieved a subjectivist understanding of morality in the course of metaethical development versus those who have achieved such an understanding or even transcended it. The first group consisted of 63 adolescents with a mean age of 14.62 years, $S D=1.69$. This group was significantly younger than the second group that included 125 participants of an average age of 17.01 years, $S D$ $=2.32, t(186)=7.24, p<.01$.

\section{Questionnaire}

Delinquent behavior. To assess adolescents' engagement in delinquent behavior a common questionnaire procedure was used: Respondents were given a list of various behaviors and asked to report whether or not they had engaged in such behavior (response format: $0=$ no vs. $1=$ yes). Such self-report measures of delinquent behavior are generally accepted as a reliable and valid measure of juvenile delinquency (Huizinga \& Elliot, 1986). Empirical studies documented considerable overlap between self-reported delinquency and official data. Patterson and Stouthamer-Loeber (1984), for instance, demonstrated that youth who were in contact with the police were almost totally a subset of self-report delinquents. Because many offenses do not appear in official records, Allen et al. (1997) consider self-report measures as the least biased procedure for the assessment of adolescents' problem behavior. In the context of the present study, 12 different kinds of delinquent behaviors were presented that are common in adolescence (e.g. shop-lifting, absence from school for a whole day without permission, minor forms of fraud and vandalism). The items were borrowed from a large-scale representative youth study with German teenagers (Wiesner \& Silbereisen, 1999). A scale analysis indicated that they can be well aggregated into a single scale 
with sufficient internal consistency, Cronbach's- $\alpha=.73$. In the present sample, the grand mean was $3.52(S D=2.62$, range $=0-11)$. Consistent with findings reported by Wiesner and Silbereisen (1999), significant effects of gender and age (represented by grade-level) were found, with males and older adolescents evidencing higher scores of self-reported delinquent behavior, $F(1,184)=$ 18.7 and $F(3,184)=4.51$ respectively, $p$ s $<.01$. In the sample, $28 \%$ of adolescents admitted that they had stolen something from a store at least once that was valued at 10 EURO or more. Shoplifting was more frequent than crimes that involved any kind of violence and property damage as evidenced, for instance, by $21 \%$ of adolescents who reported that they had destroyed public property at least once just for fun. The most common minimal offense committed by $57 \%$ of participants was "Trying to get access to a cultural event without paying the entrance fee".

Social desirability. To control for social desirability as a possible confound of adolescents' responses, social desirability response bias was assessed by the German Social Desirability Scale17 (SDS-17; Stöber, 1999). The scale was developed as a substitute for the somewhat outdated Marlow-Crowne scale. The SDS-17 is particularly suitable for assessing social desirability response bias in younger people. It has sufficient reliability and convergent as well as discriminant validity (Stöber, 2001).

\section{Results}

As described in the introduction, the present study focuses on three issues concerning selfattributed moral emotions in adolescence: (a) the relation between the intensity of self-evaluative moral emotions and adolescents' delinquency; (b) the association between self-attributed moral emotions and confidence in moral judgment as a function of metaethical stance; (c) the relation between self-reported moral emotions and adolescents' age. In the following these questions are addressed in turn. Those eight participants who did not share the assumption that all the behaviors described in the scenarios were wrong from a moral point of view (see method section) were not included in the following analyses. The final sample size therefore was $N=192$, with an almost equal distribution of participants across genders and grade-levels. If the number of cases deviates from 192 in an analysis this is due to missing values. Significance tests will be one-tailed whenever the direction of an effect has been postulated.

Adolescents' self-attributed moral emotions and delinquency. To test the hypothesis that self-reported moral emotions following a moral transgression are related to adolescents' delinquent 
behavior, a hierarchical regression analysis was run. In the first step, social desirability response bias was entered in the regression. In the second step, it was tested whether adolescents' selfreported moral emotions following a moral transgression significantly predict delinquent behavior even when social desirability is controlled. In the third step, two different regression models were tested, alternatively. Model A included two socio-demographic factors that are usually associated with adolescent delinquency, namely gender and age (e.g. Wiesner \& Silbereisen, 1999), in order to check whether moral emotion attributions contribute to the prediction of adolescents' delinquency independent of these factors. Alternatively, Model B tested to what extend the prediction of adolescents' delinquent behavior by moral emotion attributions depends on those variables of the present study that were postulated to be closely related to moral emotion attributions (confidence in moral judgment, metaethical stance as well as the interaction of metaethical subjectivism with confidence). Theoretically, it was expected that moral emotion attributions predict adolescent delinquency even when these variables are controlled. For the regression analyses adolescents' selfreported emotional reactions as well as their confidence in moral judgment were averaged across the stories and entered as a single scale. Results are summarized in Table 1.

- Insert Table 1 about here -

Social desirability was a significant predictor of adolescent delinquency. Nonetheless, entering adolescents' moral emotion attributions as assessed in the interview procedure (Step 2) yielded a significant increase in the explained variance. Adolescents with stronger self-evaluative emotional reactions were less involved in delinquent behavior. Including participants' gender and age in the regression (Step 3, Model A) again improved the prediction significantly. Both factors were significant predictors, with females as well as younger adolescents evidencing less engagement in delinquent behavior. By including participants' gender and age, the effect of moral emotions as a predictor of adolescent delinquent behavior was somewhat reduced, but remained significant. Thus, the effect of moral emotions as a predictor of delinquent behavior was not attributable to adolescents' gender and age. Alternatively, including confidence in moral judgment, metaethical stance and the interaction of confidence in moral judgment with metaethical stance as controls (Step 3, Model B) did not improve the regression significantly. Moral emotion attributions continued to be a significant predictor of delinquent behavior even when these variables were controlled. ${ }^{2}$ 


\section{Adolescents' self-attributed moral emotions and confidence in moral judgment. To}

investigate change in the association between the intensity of moral emotion attributions and confidence in moral judgment, participants' interview responses, again, were represented by single scales for confidence in moral judgment, on the one hand, and the intensity of self-evaluative moral emotions, on the other. For the full sample, the correlation between these two scales was $r(190)=$ $.53, p<.01$. This correlation was slightly reduced when social desirability response bias was partialled out, $r(189)=.50, p<.01$.

To test the hypothesis that the association between confidence in moral judgment and the intensity of moral emotion attributions is moderated by adolescents' metaethical stance, the statistical procedure proposed by Baron and Kenny (1986) was applied. Thus, two separate regressions for the two groups representing different metaethical stances were run with moral emotion attributions as dependent variable and confidence in moral judgment as predictor. The difference between the unstandardized beta-weights of the two regression equations was then tested for significance according to the formula provided by Cohen and Cohen (1983, p. 56).

For those adolescents who had not yet achieved the subjectivist metaethical position the unstandardized beta-weight of confidence in moral judgment as a predictor moral emotion attributions was $.44, p<.01$. By contrast, for those adolescents who had attained the subjectivist metaethical position in the course of development or even transcended it, the same regression coefficient equaled $.74, p<.01$. This group difference in the two regression coefficients was significant, $t=11.89, d f=184, p<.01$. Note, that this finding cannot be attributed to participants' chronological age: When the sample was split into two age groups (Grade $7+9$ versus Grade $11+$ 13) and the regression of moral emotion attributions on confidence in moral judgment was computed for the two age groups separately, the two unstandardized beta-weights were of almost equal size, with $b \mathrm{~s}=.52$ and .53 , respectively. Thus, it is metaethical development and not merely age that is relevant for the increased consistency of confidence in moral judgment and moral emotion attributions in adolescence.

Adolescents' self-attributed moral emotions and age. To investigate age-related changes in the intensity of self-attributed moral emotions a MANOVA was conducted with repeated measures on self-reported moral emotions across the four different scenarios as a within-subject factor, participants' grade level as a between subject factor and social desirability response bias as a 
covariate. The results of this analysis are summarized in Table 2. Again, there was a significant effect of social desirability $(\beta=.27, t=3.71, p<.01)$ indicating that adolescents' self-attributed moral emotions following a moral transgression are to some extent influenced by social desirability response bias. After controlling for this effect, the difference between grade levels was marginally significant. Moreover, story content, i.e. the kind of moral transgression that was described in a scenario yielded a significant effect with regard to adolescents' emotion attributions. Finally, a significant interaction of story content and grade level emerged.

- Insert Table 2 about here -

The means of adolescents' self-reported emotional reactions are documented in Table 3 . It is evident that Story II (absconding from the scene of an accident) evoked the strongest selfevaluative emotional responses, followed by Story I (giving false testimony). By contrast, emotional reactions regarding Story IV (stealing) and Story III (not returning a found wallet) were less strong. Averaged across scenarios, participants from Grade 7 tended to report the strongest self-evaluative emotional responses and participants from Grade 9 the weakest. From Grade 9 to Grade 13 the intensity of self-attributed moral emotions gradually increased. These differences, however, need to be interpreted in the broader context of a significant interaction of story content and grade level. As demonstrated in Table 3, the intensity of self-attributed moral emotions evidenced a U-shaped pattern for Story I (giving false testimony) and Story II (absconding from accident), with higher scores in Grade 7, a decrease in Grade 9 and a gradual increase in Grades 11 and 13. A different pattern was obtained for Story III (not returning found wallet) and Story IV (stealing): For these two moral transgressions the strongest negative emotional responses were obtained in Grade 7. They then declined so that in Grade 13 adolescents' self-reported negative emotional responses following these transgressions were weakest compared to all other grade levels.

- Insert Table 3 about here -

Discussion

The present study was meant to investigate adolescents' self-attributed moral emotions following a moral transgression in the broader context of adolescent development. Theoretically, it was expect that the intensity of self-evaluative emotional reactions when committing an immoral act in order to achieve a desired object is a valid indicator of adolescents' moral motivation 
strength. Results support this view: Self-attributed moral emotions as assessed in the present study predicted adolescents' engagement in delinquent behavior even when social desirability response bias, gender and age or, alternatively, confidence in moral judgment and metaethical stance were statistically controlled. This finding demonstrates that self-reported negative emotional reactions following a moral transgression are a valid indicator of individuals' moral motivation strength not only in childhood, as indicated by the happy-victimizer research paradigm, but in adolescence as well. Thus, studying moral emotions following a moral transgression provides an important bridge across the divide that separates moral judgment from moral action. At the same time, the finding points at a feature of adolescent delinquency that has not been well documented so far: adolescent delinquency apparently is not only characterized by delays in socio-moral development and cognitive distortions of antisocial behavior as described, for instance, by Gibbs (1991) as well as Gregg, Gibbs and Basinger (1994), but by particular emotional deficiencies, as well. As indicated by the findings of the present study, the experience of moral emotions following a moral transgression may be an important preventive factor for adolescent delinquency. This functional aspect of adolescents' self-attributed moral emotions appears to point to a promising line of further research.

Regarding the association between self-attributed moral emotions, on the one hand, and confidence in moral judgment, on the other, it was postulated that these two dimensions become more closely associated once adolescents achieve the subjectivist metaethical stance. This expectation was fully confirmed. Thus, in the course of adolescent development, the intensity of self-evaluative moral emotions becomes an additional source of confidence in one's moral judgment. It can either strengthen or weaken a person's moral beliefs. Theoretically, this finding supports the more general notion of an integration of self and morality in adolescence as outlined by Damon (1996) and Blasi (1995). It demonstrates that the process of coordinating moral judgment and moral emotion attributions that starts in childhood, as documented by previous happy-victimizer research, continues well into adolescence. At the same time, the finding suggests that the close connection between moral certainty and the experience of various moral emotions that is characteristic of adults' moral functioning (cf. Montada, 1993) is an outgrowth of individuals' metacognitive development. 
Apart from demonstrating that the strength of self-attributed moral emotions is an important factor in adolescent delinquent behavior, and that the development of moral emotion attributions is related to changes in underlying metaethical conceptions, the study also provided evidence for agerelated changes in the intensity of adolescents' self-attributed moral emotions. For two moral rule violations (giving false testimony and absconding from the scene of an accident) a U-shaped agerelated pattern emerged. By contrast, for the other two moral transgressions (stealing and not returning a found wallet) a gradual decrease in the strength of emotional reactions was found. Thus, the general age-related trend in moral emotion attributions that was reported repeatedly for children (shift from 'feeling good' to 'feeling bad') was not paralleled by a corresponding general increase in the intensity of self-evaluative emotional reactions in the adolescent years. Developmental change in adolescents' intensity of self-attributed moral emotions turned out to be more complex. Perhaps this greater complexity is due to a greater ability of adolescents to take situational variations into consideration. However, it also might be the case that similar variations would be found in childhood if a broader range of moral issues were included in studies with children and if the focus was on the intensity of self-evaluative emotions rather than on the qualitative shift from 'feeling good' to 'feeling bad'. Moral emotion attributions in childhood thus may be more context dependent than happy-victimizer research generally suggests. This hypothesis needs to be tested by further research.

Because the stories used in the present study do not only describe different types of moral rule violations but also vary with regard to the severity of the moral transgression, the contextual variations as obtained in the study are somewhat difficult to interpret. They might result from an increased coordination of moral judgment, moral emotion attributions and actual behavior as indicated by the present study's findings as well as other studies. Leenders and Brugman (in press) demonstrated that adolescents consider hypothetical moral transgressions as less immoral and less severe than if they actually had committed similar transgressions by themselves. Moral transgressions that are considered as less severe by adolescents may become less likely to evoke strong moral emotions over the course of development, whereas the contemplation of severe transgressions might strengthen self-evaluative emotional reactions. These complex relations between the intensity of self-evaluative moral emotions, the severity of moral transgressions, adolescents' actual behavior and age needs to be disentangled by future research. 
Besides the present study's ambiguity concerning the interpretation of age-related changes in moral emotion attributions, it should be explicitly noted that the design of this study generally might have led to an overestimation of the intensity of moral emotions: Respondents were first asked about the moral rightness of the transgression and the confidence in their judgment before they were asked how they would feel after committing such a transgression. The demand characteristics created by the first two questions may have primed adolescents to use certain normative concepts when answering the third question they might not have been accessed spontaneously on their own. Although, in the study, no effect of story order was found that would indicate a cumulative priming effect, this is a serious limitation of the present study. Because of this limitation, the general finding that "happy victimizers" were almost non-existent in the adolescent sample needs to be interpreted cautiously. 


\section{References}

Allen, J. P., Philliber, S., Herrling, S., \& Kuperminc, G. P. (1997). Preventing teen pregnancy and academic failure: Experimental evaluation of a developmentally based approach. Child Development, 22, 729-742.

Arsenio, W. F., \& Kramer, R. (1992). Victimizers and their victims: Children's conceptions of the mixed emotional consequences of moral transgressions. Child Development, 63, 915-927.

Asendorpf, J. B., \& Nunner-Winkler, G. (1992). Children's moral motive strength and temperamental inhibition reduce their immoral behavior in real moral conflicts. Child Development, 63, 1223-1235.

Baron, R. \& Kenny, D. (1986). The moderator-mediator variable distinction in social-psychological research: conceptual strategic, and statistical considerations. Journal of Personality and Social Psychology, 51, 1173-1182.

Bergman, R. (2002). Why be moral? A conceptual model from developmental psychology. Human Development, 45, 104-124.

Blasi, A. (1993). Die Entwicklung der Identität und ihre Folgen für moralisches Handeln [The development of identity and its consequences for moral action]. In W. Edelstein, G. NunnerWinkler, \& G. Noam (Hrsg.), Moral und Person (S. 119-147). Frankfurt/M.: Suhrkamp.

Blasi, A. (1995). Moral understanding and the moral personality: The process of moral integration. In W. M. Kurtines \& J. L. Gewirtz (Eds.), Moral development: An introduction (pp. 229253). Boston: Allyn and Bacon.

Cohen, J. \& Cohen, P. (1983). Applied multiple regression/correlation analysis for the behavioral sciences. Hillsdale: Erlbaum.

Damon, W. (1996). The lifelong transformation of moral goals through social influence. In P. B. Baltes \& U. M. Staudinger (Eds.), Interactive minds (pp. 198-220). Cambridge: Cambridge University Press.

Damon, W., \& Hart, D. (1988). Self-understanding in childhood and adolescence. New York: Cambridge University Press.

Gibbs, J. C., Clark, P. M., Joseph, J. A., Green, J. L., Goodrick, T. S., \& Makowski, D. G. (1986). Relations between moral judgment, moral courage, and field independence. Child Development, 57, 185-193. 
Gibbs, J. C. (1991). Sociomoral developmental delay and cognitive distortion: Implications for the treatment of antisocial youth. In W. M. Kurtines \& J. L. Gewirtz (Eds.), Handbook of moral behavior and development (Vol. 3) (pp. 95-110). Hillsdale: Erlbaum.

Gregg, W., Gibbs, J. C. \& Basinger, K. S. (1994). Patterns of developmental delay in moral judgment by male and female delinquents. Merrill-Palmer Quarterly, 40, 538-553.

Hallett, D., Chandler, M. J., \& Krettenauer, T. (2002). Disentangling the course of epistemic development: parsing knowledge by epistemic content. New Ideas in Psychology, 20, 285307.

Harris, P. L. (1989). Children and Emotion. Oxford: Blackwell.

Hughes, C., \& Dunn, J. (2000). Hedonism or empathy? Hard-to-manage children's moral awareness and links with cognitive and maternal characteristics. British Journal of Developmental Psychology, 18, 227-245.

Hofer, B. K., \& Pintrich, P. R. (1997). The development of epistemological theories: Beliefs about knowledge and knowing and their relation to learning. Review of Educational Research, 67, 88-140.

Huizinga, D., \& Elliott, D. S. (1986). Reassessing the reliability and validity of self-report delinquency measures. Journal of Quantitative Crimonology, 2, 293-327.

Keller, M., Lourenço, O., Malti, T., \& Saalbach, H. (2003). The multifaceted phenomenon of 'happy victimizers': A cross-cultural comparison of moral emotions. British Journal of Developmental Psychology, 21, 1-18.

Kitchener, R. F. (2002). Folk epistemology: An introduction. New Ideas in Psychology, 20, 89-105. Kohlberg, L. \& Candee, D. (1984). The relationship of moral judgment to moral action. In L. Kohlberg (Ed.), The psychology of moral development (pp. 499-581). San Francisco: Harper \& Row.

Krettenauer, T. (2004). Metaethical cognition and epistemic reasoning development in adolescence. International Journal of Behavioral Development, 28, 461-470.

Krettenauer, T. (in press). The role of epistemic cognition in adolescent identity formation: Further evidence. Journal of Youth and Adolescence. 
Kuhn, D. (1999). Metacognitive development. In L. Balter \& C. S. Tamis-LeMonda (Eds.), Child psychology: A handbook of contemporary issues (pp. 259-286). Philadelphia: Psychology Press.

Kuhn, D., Cheney, R., \& Weinstock, M. (2000). The development of epistemological understanding. Cognitive Development, 15, 309-328.

Leenders, I. \& Brugman, D. (in press). Moral/Non-Moral domain shifs in young adolescents in relation to delinquent behavior. British Journal of Developmental Psychology.

Lourenço, O. (1997). Children's attributions of moral emotions to victimizers: Some data, doubts and suggestions. British Journal of Developmental Psychology, 15, 425-438.

Malti, T. (2003). Das Gefühlsverständnis aggressiver Kinder [Aggressive children's understanding of emotions]. Doctoral dissertation, Free University Berlin. [on-line] Available: www.diss.fu-berlin.de/2003/120/index.html.

Mansfield, A. F. \& Clinchy, B. M. (2002). Toward an integration of objectivity and subjectivity: epistemological development from 10 to 16. New Ideas in Psychology, 20, 225-262.

Montada, L. (1993). Moralische Gefühle [Moral emotions]. In W. Edelstein, G. Nunner-Winkler, \& G. Noam (Eds.), Moral und Person (S. 259-277). Frankfurt/M.: Suhrkamp.

Moshman, D. (2005). Adolescent psychological development ( $2^{\text {nd }}$ ed.). Mahwah, NJ: Erlbaum. Murgatroyd, S. J., \& Robinson, E. J. (1993). Children's judgements of emotion following moral transgression. International Journal of Behavioral Development, 16, 93-111.

Murgatroyd, S. J., \& Robinson, E. J. (1997). Children's and adults' attributions of emotion to a wrongdoer: The influence of the onlooker's reaction. Cognition and Emotion, 11, 83-101.

Nucci, L. P. (2001). Education in the moral domain . Cambridge: Cambridge University Press.

Nunner-Winkler, G. (1999). Development of moral understanding and moral motivation. In F. E.

Weinert \& W. Schneider (Eds.), Individual development from 3 to 12 (pp. 253-292). Cambridge: Cambridge University Press.

Nunner-Winkler, G., \& Sodian, B. (1988). Children's understanding of moral emotions. Child Development, 59, 1323-1338.

Patterson, G. R. \& Stouthamer-Loeber, M. (1984). The correlation of family management practices and delinquency. Child Development, 55, 1299-1307. 
Smetana, J. (1995). Morality in context: Abstractions, ambiguities, and applications. Annals of Child Development, 10, 83-130.

Stöber, J. (1999). Die Soziale-Erwünschtheits-Skala-17: Entwicklung und erste Befunde zu Reliabilität und Validität [The social Desirability Scale 17: Development and first results on reliability and validity]. Diagnostica, 45, 173-177.

Stöber, J. (2001). The Social Desirability Scale-17 (SDS-17): Convergent validity, discriminant validity, and relationship with age. European Journal of Psychological Assessment, 17, 222232.

Treiman, D. J. (1977). Occupational prestige in a comparative perspective. New York: Academic Press.

Turiel, E. (1998). The development of morality. In W. Damon (Eds.), Handbook of child psychology (Vol. 3) (pp. 863-932). New York: Wiley.

Wiersma, N., \& Laupa, M. (2000). Young children's conceptions of the emotional consequences of varied social events. Merill-Palmer Quarterly, 46, 325-341.

Wiesner, M., \& Silbereisen, R. K. (1999). Delinquentes Verhalten in Ost und West: Jahreshäufigkeit, Schweregrad und Verlaufsmuster [Delinquent behavior in East and West: annual frequency, severity and patterns of change]. In R. K. Silbereisen \& J. Zinnecker (Eds.), Entwicklung im sozialen Wandel (pp. 251-269). Weinheim: Psychologie Verlags Union.

Yuill, N., Perner, J., Pearson, A., Peerbhoy, D., \& van den Emde, J. (1996). Children's changing understanding of wicked desires: From objective to subjective and moral. British Journal of Developmental Psychology, 14, 457-475. 


\section{Appendix A}

Scenarios describing moral transgressions (translated from German)

\section{Story I (false testimony)}

A young man was accused of robbery and of physically assaulting his victim. There is no proof that he is actually guilty. However, there is one witness, Simone. Simone is 18 years old, she has no job training and she is unemployed. The father of the suspect promises Simone a job in his company, if she willing to exonerate his son. Simone knows that the suspect actually committed the crime. Nonetheless, in court she makes a statement that largely exculpates the suspect. - What do you think: Was Simone right to do what she did?

Story II (absconding from accident)

It is rather late in the evening and Stefan is driving home from a party in his car. He had drunk a lot of beer during the party and he is no longer sober. In the darkness, Stefan overlooks a motorbike and runs into it. The rider falls off the bike, but does not appear to be severely injured. Stefan is afraid of being caught for drinking and driving. He therefore speeds up and drives away. What do you think: Was Stefan right to do what he did?

\section{Story III (not returning found wallet)}

On her way home from school, Jana, a 16-year-old girl, notices a wallet lying on the sidewalk. Inside the wallet she finds the identity card of the owner as well as 130 EURO cash. Jana takes the money and leaves the wallet lying on the ground. - What do you think: Was Jana right to do what she did?

\section{Story IV (stealing)}

Oliver, a student, has a very unique hobby. He collects old records with original hits from the 50s. He already has a considerable collection, but also misses several pieces. One Sunday morning, while strolling over the flea market, Oliver finds an album, he had been searching for a long time. The salesman, however, wants 50 EURO for the album - a price Oliver cannot afford. At the right moment, Oliver takes the album and disappears in the crowd. - What do you think: Was Oliver right to do what he did? 
Appendix B.

Summary of Metaethical Stances as Defined across Various Issues of Metaethical Cognition

Certainty of moral judgment Relativity of moral judgment Mechanisms of belief change Sources of decision-making

\begin{tabular}{|c|c|c|c|c|}
\hline Intuitionism & $\begin{array}{l}\text { certainty depends on exernal } \\
\text { circumstances (e.g. } \\
\text { predictability of consequences } \\
\text { of a decision) }\end{array}$ & $\begin{array}{l}\text { a moral judgment is either } \\
\text { right or wrong; in general, } \\
\text { there is one single right } \\
\text { answer to a moral problem }\end{array}$ & $\begin{array}{l}\text { moral belief change is } \\
\text { induced by external factors } \\
\text { (e.g. persuasion) or otherwise } \\
\text { unexplicable }\end{array}$ & $\begin{array}{l}\text { experts and authorities } \\
\text { guarantee correctness of } \\
\text { decisions }\end{array}$ \\
\hline Subjectivism & $\begin{array}{l}\text { certainty depends on the degree } \\
\text { of subjective ambivalence and } \\
\text { indecision }\end{array}$ & $\begin{array}{l}\text { a moral judgment is neither } \\
\text { right nor wrong, but reflects } \\
\text { mere subjective opinion; } \\
\text { anything goes }\end{array}$ & $\begin{array}{l}\text { moral beliefs change by } \\
\text { putting oneself in the shoes of } \\
\text { others and taking a different } \\
\text { personal stance }\end{array}$ & $\begin{array}{l}\text { the perspective of those } \\
\text { directly concerned by a } \\
\text { decision is most important }\end{array}$ \\
\hline Transsubjectivism & $\begin{array}{l}\text { certainty depends on the } \\
\text { possibility to justify one's own } \\
\text { judgment in the face of } \\
\text { conflicting moral claims }\end{array}$ & $\begin{array}{l}\text { moral judgments are } \\
\text { considered as more or less } \\
\text { well-founded; some answers } \\
\text { might be better justified than } \\
\text { others }\end{array}$ & $\begin{array}{l}\text { beliefs change by readjusting } \\
\text { the underlying evaluative } \\
\text { perspective, that combines } \\
\text { personal commitment with } \\
\text { the need for justification; the } \\
\text { process judgment formation } \\
\text { is in principle open ended }\end{array}$ & $\begin{array}{l}\text { the perspective that appears } \\
\text { to be most comprehensive } \\
\text { and that best balances } \\
\text { conflicting moral claims is } \\
\text { decisive }\end{array}$ \\
\hline
\end{tabular}




\section{Footnotes}

${ }^{1}$ The transsubjectivist metaethical stance, by contrast, is not achieved very often in adolescence. Theoretically, the transition from subjectivism to transsubjectivism is not considered particularly relevant for the process of integrating self and morality. It is therefore left out of consideration in the context of the present study.

${ }^{2}$ Because scores of self-reported delinquent behavior are generally not normally distributed (as was the case in the context of the present study), the regression analysis was run also with normalized scores of delinquent behavior as the dependent variable. The findings did not change due to the variable transformation. 
Table 1. Summary of Regression Analysis Predicting Delinquent Behavior

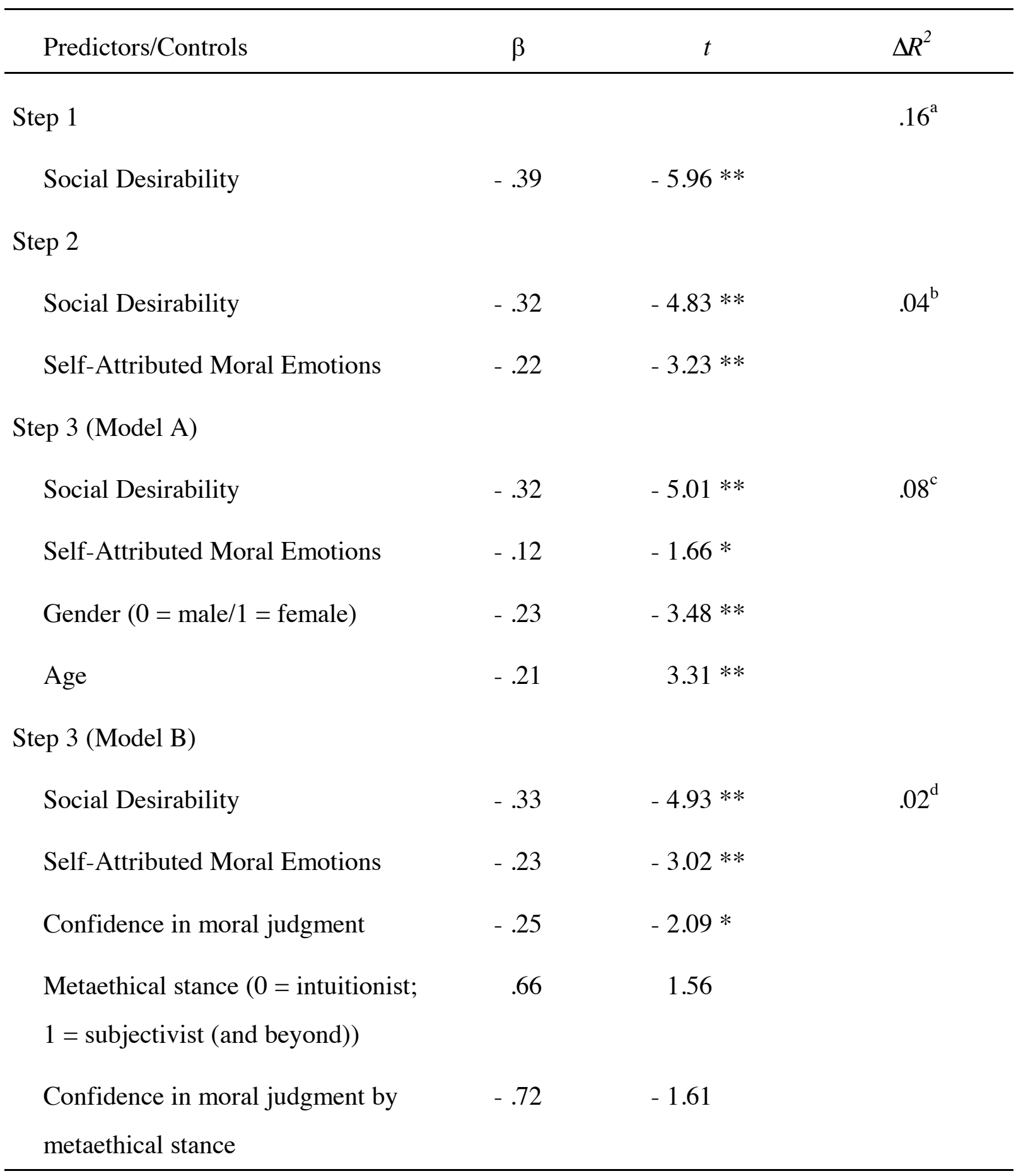

${ }^{\mathrm{a}} F(1,190)=35.57, p<.01$

${ }^{\mathrm{b}} \Delta F(1,189)=10.43, p<.01$

${ }^{\mathrm{c}} \Delta F(2,187)=11.05, p<.01$

${ }^{\mathrm{d}} \Delta F(3,182)=1.47, \mathrm{p}=.22$

$* p<.05, * * p<.01$ 
Table 2

MANOVA of Self-Attributed Moral Emotions by Adolescents' Grade Level and Story

Factors/Covariates

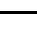

Grade level

Social desirability

Error

178

$d f$

Between subjects
2.52

13.79

(2.97)

Within subjects

Story

Story by Grade level

Error
3

9

537
50.48

3.90

(1.13)
.06

.00

$p$ 
Table 3

Means of the Intensity of Self-Attributed Moral Emotions by Grade level and Story

\begin{tabular}{lccccc} 
& \multicolumn{5}{c}{ Grade } \\
\cline { 2 - 5 } Story (content) & 7 & 9 & 11 & 13 & Total \\
\hline I (false testimony) & $4.81(1.36)$ & $4.19(1.42)$ & $4.24(1.30)$ & $4.58(1.12)$ & $4.45(1.33)$ \\
II (absconding from accident) & $5.29(0.72)$ & $5.17(1.09)$ & $5.33(0.87)$ & $5.37(0.85)$ & $5.29(0.89)$ \\
III (not returning found wallet) & $4.26(1.52)$ & $3.98(1.44)$ & $4.17(1.45)$ & $3.69(1.39)$ & $4.03(1.46)$ \\
IV (stealing) & $5.11(1.27)$ & $4.15(1.46)$ & $3.85(1.46)$ & $3.77(1.51)$ & $4.23(1.48)$ \\
\hline Total & $4.89(0.84)$ & $4.37(0.92)$ & $4.41(0.81)$ & $4.46(0.99)$ & $4.53(0.91)$
\end{tabular}

Note. Numbers in parentheses indicate standard-deviations. 